DIW BERLIN

Discussion

Papers
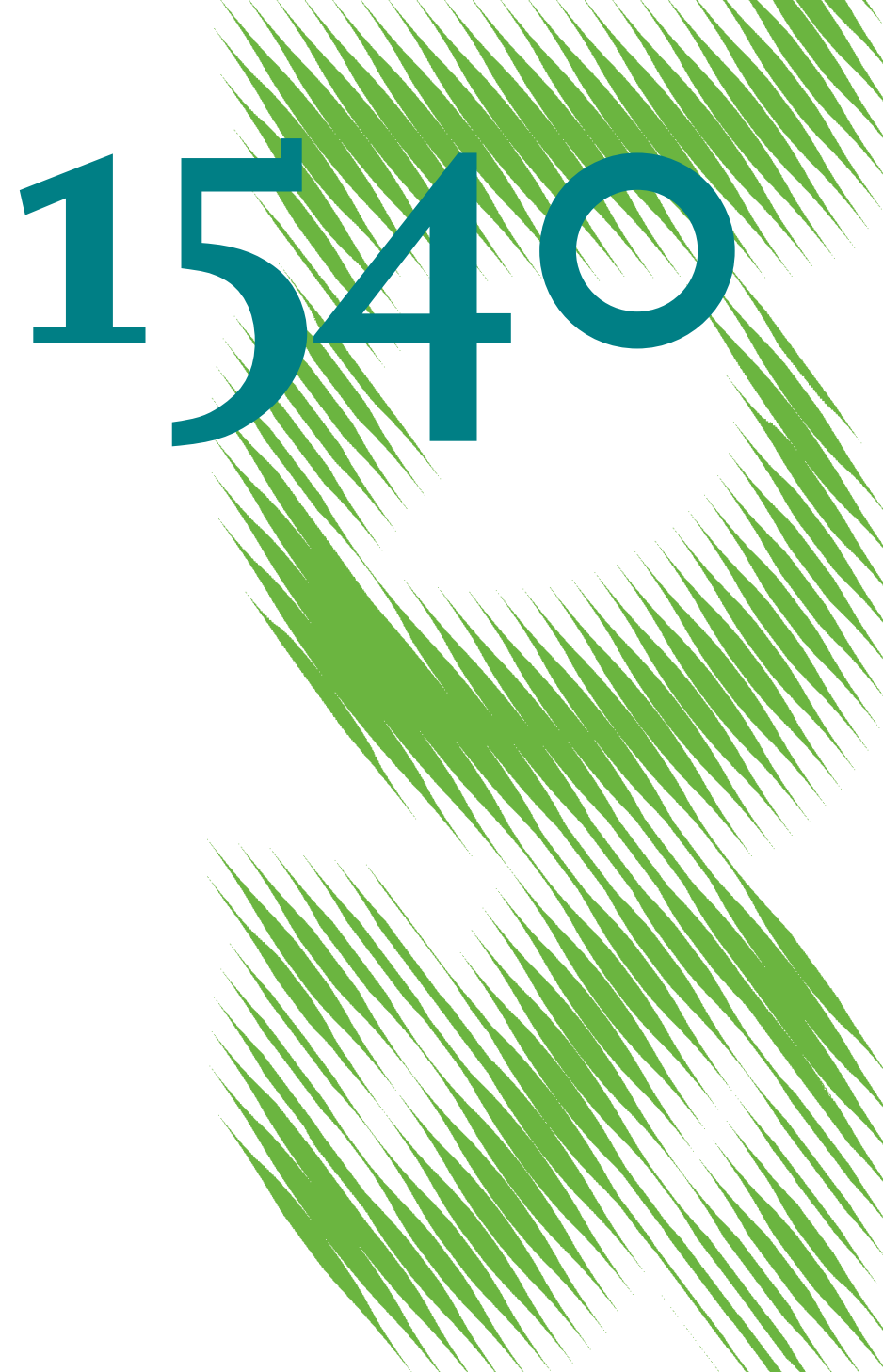

On Start-up Costs of Thermal Power Plants in Markets with Increasing Shares of Fluctuating Renewables 
Opinions expressed in this paper are those of the author(s) and do not necessarily reflect views of the institute.

IMPRESSUM

(C) DIW Berlin, 2016

DIW Berlin

German Institute for Economic Research

Mohrenstr. 58

10117 Berlin

Tel. +49 (30) $89789-0$

Fax +49 (30) $89789-200$

http://www.diw.de

ISSN electronic edition 1619-4535

Papers can be downloaded free of charge from the DIW Berlin website:

http://www.diw.de/discussionpapers

Discussion Papers of DIW Berlin are indexed in RePEc and SSRN:

http://ideas.repec.org/s/diw/diwwpp.html

http://www.ssrn.com/link/DIW-Berlin-German-Inst-Econ-Res.html 


\title{
On Start-up Costs of Thermal Power Plants in Markets with Increasing Shares of Fluctuating Renewables
}

\author{
Wolf-Peter Schill, ${ }^{*}$, Michael Pahle $^{* *}$, Christian Gambardella $^{* *}$
}

\begin{abstract}
The emerging literature on power markets with high shares of fluctuating renewables suggests that more frequent start-up procedures of thermal power plants may become an increasing concern, both for costs and possibly also for market design. Based on official scenario assumptions, we investigate how start-ups and related costs develop in Germany, where the share of fluctuating renewables quadruples between 2010 and 2030. We find that the overall number of start-ups decreases by a third, while related costs increase by half. The relative share of start-up costs in overall variable costs of thermal plants grows only slightly and remains below $1 \%$. Several overlapping effects drive these results. The expansion of fluctuating renewables alone would strongly increase start-up costs. In contrast, increased flexibility of biomass power plants, additional power storage and larger block sizes have opposite effects. While the relevance of start-up costs grows only moderately under baseline assumptions, it may increase further under alternative developments of system flexibility. Future power market design reforms should thus aim to ensure proper remuneration of quasi-fixed start-up costs. Our findings are also relevant for many other countries with thermal power systems that plan to undergo comparable transitions toward fluctuating renewables.
\end{abstract}

JEL: Q41; Q47

Keywords: Power sector modeling; start-up costs; unit commitment; renewables

We thank Jochen Diekmann, Philipp Hanemann, Claudia Kemfert, Friedrich Kunz, Karsten Neuhoff, Oliver Tietjen as well as the participants of the July 2015 Strommarkttreffen in Berlin and the Berlin Conference on Energy and Electricity Economics 2015 for valuable comments on earlier drafts. We also thank Stiftung Mercator and Agora Energiewende for funding this research as part of the project "A Renewable Energy Dominated Power Market: Challenges \& Solutions for Market Design and Policy Instruments". The views expressed here are our own.

\footnotetext{
*German Institute for Economic Research (DIW Berlin), Mohrenstr. 58, 10117 Berlin.

**Potsdam Institute for Climate Impact Research (PIK), Telegrafenberg, 14473 Potsdam.

\#Corresponding author. Contact: Phone: ++49-30-89789-675, Email: wschill@diw.de.
} 


\section{Introduction}

In the context of the German energy transition, the federal government aims to increase the share of renewable power generation to at least $80 \%$ of gross power consumption by 2050 . Because of limited hydro, biomass and geothermal resources, which would allow for dispatchable renewable power generation, the expansion focuses on fluctuating renewable sources such as wind and solar power. In the long run, these sources are projected to account for the largest part of German power generation. Accordingly, the residual load of the German power system, which has to be served by thermal power plants, power storage, and the demand side, will also become more fluctuating. ${ }^{1}$ In consequence, the operation of the remaining thermal power plants has to change compared to former base- and mid-load cycling patterns (Pérez-Arriaga and Batlle 2012).

That is, thermal plants are assumed to start up and shut down more frequently with increasing renewable supply fluctuations. Before a thermal plant can feed electricity to the grid, it has to be started up, i.e. ramped up at least to the minimum generation level. As explained by Stoft (2002), this usually comes at a cost independent of how much output is produced. The size of these quasi-fixed costs stemming from wear and tear as well as the fuel required to heat up the steam cycle depends on the type and size of a particular plant. Different market jurisdictions have established different ways to allow for generators to make their bids more complex in order to secure remuneration for these costs when bidding into a specific market (Gribik et al. 2007, Grimm et al. 2008) ${ }^{2}$. Under certain circumstances, complex bidding can entail inefficient market clearing results (O'Neill et al. 2005, Grimm et al. 2008, Meeus et al. 2009). Consequently, an increasing number of start-ups may not only incur additional system costs, but could also come along with an increased volume of complex bidding which, in turn, could affect short-run allocative market efficiency.

In this paper we study how an expansion of fluctuating renewables affects the number of start-ups of conventional power plants and respective costs. We apply a numerical optimization model with a unit commitment formulation to different scenarios of the German power system for the years 2010, 2020 and 2030, based on projections of the German Grid Development Plan (50Hertz et al. 2013). In doing so, we separate the effects of increasing renewable capacities and other changes in the power plant portfolio. By means of sensitivity analyses we also analyze the effects of alternative developments of renewable expansion, power storage, minimum load levels of thermal power plants, and decreased renewable curtailment. We find that the overall number of start-ups decreases by a third between 2010 and 2030, mainly due to a change in the generation portfolio towards larger block sizes and additional supply-side flexibility. At the same time, start-up costs increase by half, amongst other factors because of the assumed growth in fuel and carbon emission prices. Yet due to a nearly simultaneous increase of quasi-fixed costs and other variable generation costs, the share of the former in overall short-run costs increases only slightly under baseline assumptions. The relevance of start-up costs may increase further under the assumption of lower system flexibility.

\footnotetext{
${ }^{1}$ Schill (2014) shows how the German residual load curve develops under different assumptions on renewable deployment and system flexibility. In particular, hourly gradients of residual load increase. While the largest hourly increase and decrease in residual load were +11 GW and $-7 \mathrm{GW}$ in 2010, these values grow to $+22 \mathrm{GW}$ and $-27 \mathrm{GW}$ in 2032.

${ }^{2}$ In centrally dispatched pool markets such as PJM in the U.S., nodal spot prices computed by independent system operators have to reflect start-up costs while some use uplift or make-whole payments (Gribik et al., 2007). In contrast, most European power markets are self-dispatched and bilateral implying the use of linear (non-discriminatory) pricing, where start-up costs and minimum load levels of thermal power plants are reflected in block bids over several consecutive hours.
} 
The issue of quasi-fixed start-up costs should thus be properly addressed in future power market design reforms.

Our study relates to and complements previous work in several respects. A broad literature has shown that the demand for power system flexibility increases with growing shares of fluctuating renewables (cp. Kondziella and Bruckner 2016). While there is a widespread general notion that this increases the cycling needs of thermal power plants and respective costs (VTT 2009, Bertsch et al. 2014), there is little research explicitly focusing on this issue. Pérez-Arriaga and Batlle (2012) qualitatively argue that cycling costs of thermal plants increase for growing shares of wind and solar power, and that such costs increase proportionally depend on the capacity of power plants with limited flexibility in the system. In a numerical analysis for the Irish system, Troy et al. (2010) show that growing shares of wind power have substantial effects on operating costs of former base-load plants which were not designed for frequent cycling. Yet they do not account for longer-term changes in the generation portfolio as we do. Based on a linear cost minimization model, Bertsch et al. (2014) argue that specific incentives for thermal flexibility are not required in Europe even in case of very high renewable shares as long as the market design incentivizes an adequate least-cost power plant portfolio. While they do consider some flexibility restrictions of thermal plants as well as long run changes in the generation portfolio, they do not quantify specific start-up cost outcomes or changes related to the diffusion of variable renewables. The same is also true for Herrero et al. (2015), who study the long-term effect of linear vs. non-linear pricing rules in the context of increasing renewable shares with a unit commitment cost minimization model and only conclude that linear pricing may promote a more efficient portfolio in the long term.

Hence, while the cited literature includes qualitative indications that cycling needs of thermal power plants generally increase for higher shares of fluctuating renewables, quantitative analyses of startup processes and respective costs are missing. Such analyses should not only reflect increasing renewables, but also the changes in the power plant portfolio that are likely to accompany the expansion of renewables. These include a shift to more flexible plants and additional storage capacity, which also affects thermal cycling needs. Our analysis aims to contribute to the literature in this respect. As start-up costs may be interpreted as an indicator for potential inefficiencies of linear pricing schemes, we also aim to contribute to the debate on power market design for high shares of fluctuating renewables.

While the numerical analysis focuses on Germany, the expansion of wind and solar power is not an exclusive German trend. In contrast, these fluctuating renewables are increasingly applied around the world, and are very likely to play a major role in many countries in the future (cp. Milligan et al. 2015). According to the International Energy Agency's 2015 World Energy Outlook, global capacities of wind power and photovoltaics are projected to grow substantially between 2015 and 2040 with gross capacity additions of $1.5 \mathrm{TW}$ and $1.1 \mathrm{TW}$, respectively (IEA 2015). ${ }^{3}$ Our analysis is thus also relevant for many other countries with thermal power systems that plan to undergo comparable transitions toward fluctuating renewables.

The remainder is structured as follows. Section 2 introduces the analytical model formulation. Input parameters and scenarios are described in section 3. Sections 4.1 and 4.2 present model results for

\footnotetext{
${ }^{3}$ These numbers relate to the central scenario 'New Policies'. In the ' 450 Scenario', which is oriented at the $2^{\circ} \mathrm{C}$ climate goal, capacity additions are even larger. In these two scenarios, wind power and photovoltaics together account for $13 \%$ or $22 \%$ of worldwide electricity generation in 2040 .
} 
the baseline scenario and four sensitivities, respectively. Major model limitations and their qualitative effects on model outcomes are discussed in 5 . The final section concludes.

\section{The unit commitment model}

We use the unit commitment model described in Schill and Gerbaulet (2015), which minimizes total dispatch costs of the power plant fleet. ${ }^{4}$ Costs and restrictions related to starting up individual blocks are represented with a mixed-integer unit commitment formulation. The model has an hourly resolution and is solved for a full year. For numerical reasons, the model is not solved in one instance; instead, 13 consecutive sequences are solved sequentially, each covering four weeks (672 hours). For each power plant block, the operational status of the first hour of each four-week sequence is fixed to the respective value of the last hour of the previous sequence. In the very first hour, the operational status of all blocks can be freely chosen without incurring start-up costs.

Exogenous model inputs include hourly load, which is assumed to be completely price-inelastic, hourly availability profiles of fluctuating renewables, a yearly energy cap for biomass, and variable generation costs. In addition, start-up costs, minimum off-times and minimum load levels are required inputs for thermal power plants. Endogenous model variables include the hourly unit commitment of all generation and storage capacities as well as overall dispatch costs of the system. The number of start-ups and the extent of start-up costs can also be calculated for specific blocks or technology groups.

In the following, we present the analytical formulation of the model. Exogenous parameters are set in lower case letters, endogenous continuous variables have an initial upper case letter, and binary variables are completely set in upper case letters. A list of sets, parameters and variables is provided in the Appendix (Table 3).

$$
\begin{aligned}
& \text { Cost }=\sum_{i, t}\left(v c_{i} Q_{i, t}+s c_{i} S T_{i, t}\right)+\sum_{j, t} v_{s t c_{j}} S_{t o u t} t_{j, t}+\sum_{t, r e s} \text { penalty }_{\text {res }} \text { Rescurt }_{r e s, t} \\
& Q_{i, t} \leq \operatorname{qmax}_{i} \text { avail }_{i, t} U_{i, t} \quad \forall i, t \\
& Q_{i, t} \geq \operatorname{qmin}_{i} \text { avail }_{i, t} U_{i, t} \quad \forall i, t \\
& S T_{i, t} \geq U_{i, t}-U_{i, t-1} \quad \forall i, t \\
& U_{i, t-1}-U_{i, t} \leq 1-U_{i, t t} \quad \forall i, t \text { with } \\
& t \leq t t \leq t+\text { stime }_{i}-1 \\
& \text { Resint }_{r e s, t}+\text { Rescurt }_{r e s, t}=\text { resavail }_{r e s, t} \quad \forall r e s, t \\
& \text { Rescurt }_{\text {res }, t} \leq \text { resavail }_{\text {res }, t} \quad \forall r e s, t
\end{aligned}
$$

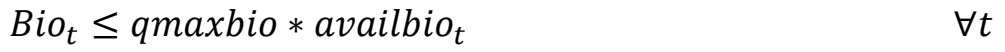

$$
\begin{aligned}
& \sum_{t} \text { Bio }_{t} \leq \text { energymaxbio } \\
& \text { Stlev }_{j, t}=\text { Stlev }_{j, t-1}+\operatorname{Stin}_{j, t} \eta_{j}-\text { Stout }_{j, t} \quad \forall j, t \\
& \text { Stlev }_{j, t} \leq \text { stlevmax }_{j} \quad \forall j, t
\end{aligned}
$$

\footnotetext{
${ }^{4}$ In contrast to the version presented in Schill and Gerbaulet (2015), the model used here does not include electric vehicles in order not to unnecessarily complicate the analysis.
} 


$$
\begin{array}{cr}
\text { Stin }_{j, t} \leq \text { stinmax }_{j} & \forall j, t \\
\text { Stout }_{j, t} \leq \text { stoutmax }_{j} & \forall j, t \\
\sum_{i} Q_{i, t}+\sum_{\text {res }} \text { Resint }_{\text {res, },}+\text { Bio }_{t}+\text { othergen }_{t}+\sum_{j}\left(\text { Stout }_{j, t}-\text { Stin }_{j, t}\right) & \\
=\text { dem }_{t}+\text { netexports }_{t} & \forall t
\end{array}
$$

The objective function (1) sums up variable generation costs of thermal plants, including start-up costs of single blocks and variable storage costs. Renewables are assumed to be dispatched without variable costs. Equations (2) and (3) represent maximum and minimum generation levels of thermal blocks. The binary status variable $U_{i, t}$ is 1 if the plant is online and 0 otherwise. Equation (4) ensures consistency between the binary status and start-up variables of thermal blocks. Equation (5) enforces a minimum off-time. Equations (6) and (7) determine hourly system integration as well as curtailment of fluctuating renewables. Equation (8) constitutes an hourly power generation capacity restriction for biomass, whereas (9) constrains overall biomass utilization to a yearly cap. Equation (10) connects the storage energy levels of subsequent periods, given hourly charging and discharging activities. Roundtrip efficiency losses are attributed to storage loading. Equations (11) to (13) represent upper limits on the storage level, the loading capacity, and the discharging capacity, respectively. The market clearing condition (14) ensures that overall supply equals demand in all hours.

It should be noted that thermal power plants (including nuclear power) are modeled as single blocks, subject to start-up costs and restrictions, while fluctuating renewables and pumped hydro storage are represented as linearized, aggregated capacities which are assumed to be perfectly flexible. Accordingly, thermal generation $\left(Q_{i, t}\right)$ is flexibility-constrained, whereas fluctuating renewable feedin $\left(\right.$ Resint $\left._{r e s, t}\right)$, generation from biomass $\left(\right.$ Bio $\left._{t}\right)$ and storage output $\left(S t o u t_{j, t}\right)$ are not. ${ }^{5}$ Inflexible power generation from run-of-river hydro and waste incineration (othergen ${ }_{t}$ ) are treated as exogenous input parameters.

\section{Input data and scenarios}

We apply the model to the German power system using scenarios of the years 2010, 2020, and 2030. The year 2010 provides a meaningful reference for comparisons as it is the year before the start of the German nuclear phase-out, and renewable capacities-particularly photovoltaics (PV)-were still relatively moderate. Input parameters of the baseline scenarios for the years 2020 and 2030 heavily lean on the medium projections of the German Grid Development Plan (NEP). This scenario was drafted by German transmission operators and approved by the federal regulator after a series of public consultations. As the NEP serves as the basis for federal German grid requirement legislation, it can be considered an official reference scenario, and is accordingly also used in many other studies. ${ }^{6}$

\footnotetext{
${ }^{5}$ More details on biomass flexibility assumptions are provided in the next section.

${ }^{6}$ We draw on the medium projections of the 2013 version of the Grid development plan (50Hertz et al. 2013) and linearly interpolate capacities for the years 2020 and 2030. The same methodology is applied in Schill and Gerbaulet (2015).
} 


\subsection{Generation capacities}

According to NEP, nuclear capacity decreases from more than $18 \mathrm{GW}$ in 2010 to less than $9 \mathrm{GW}$ by 2020 and zero by 2030, while at the same time renewable capacity increases substantially (Figure 1 ). In 2020, onshore wind power reaches $44 \mathrm{GW}$ (61 GW in 2030), offshore wind power $13 \mathrm{GW}$ (24 GW) and photovoltaics $51 \mathrm{GW}$ (59 GW). Lignite capacity moderately decreases from around $18 \mathrm{GW}$ in 2010 to 14 GW in 2030, hard coal from 24 GW to 22 GW, respectively. ${ }^{7}$ Natural gas-fired capacity strongly increases from 24 GW in 2010 to nearly 39 GW in 2030, with combined cycle gas turbines (CCGT) constituting the major fraction and open cycle gas turbines (OCGT) the minor one. ${ }^{8}$ As for pumped hydro storage, a substantial capacity increase is projected from $6.4 \mathrm{GW}$ in 2010 to $8.7 \mathrm{GW}$ in 2020 and $11 \mathrm{GW}$ in 2030. We abstract from other storage technologies, i.e. the set $J$ only includes pumped hydro storage.

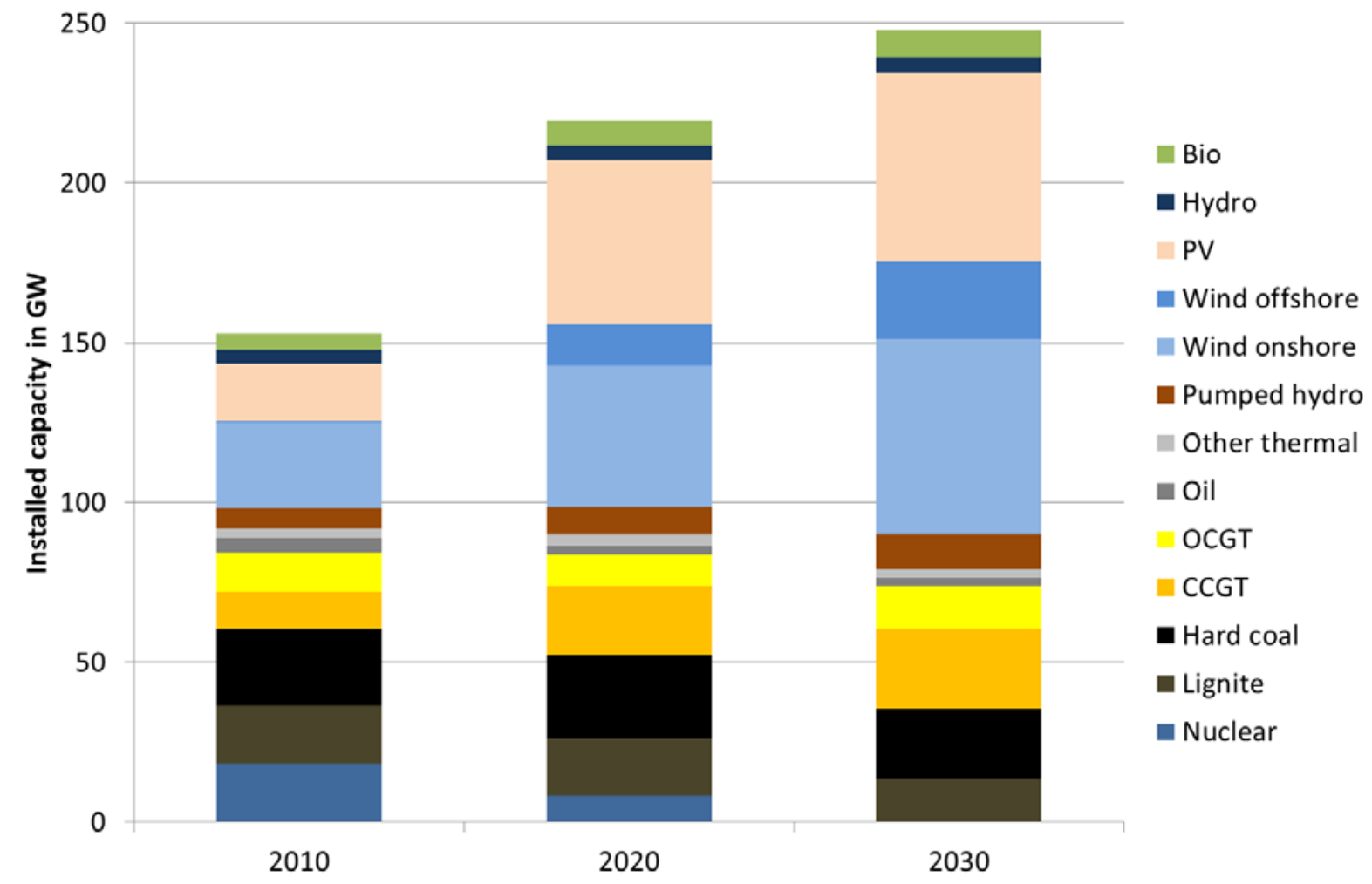

Figure 1: Installed capacities in the baseline scenarios

The aggregated capacities shown in Figure 1 are translated into a block-sharp power plant portfolio by drawing on DIW Berlin's power plant database, which, amongst other sources, builds on the commercial Platts database. In order to reduce the computational burden of the program, thermal blocks smaller than $100 \mathrm{MW}$ are aggregated to stylized $100 \mathrm{MW}$ blocks. Existing blocks are assumed

\footnotetext{
${ }^{7}$ At the time of writing, the German government put forward a legislative proposal (Strommarktgesetz), according to which seven existing lignite blocks would be transferred into a new type of reserve between 2016 and 2019 and shut down permanently four years later.

${ }^{8}$ The NEP does not include details on CCGT and OCGT capacities. The distribution between these technologies for the years 2020 and 2030 is based on own assumptions, taking into account a number of actual CCGT projects.
} 
to be shut down after they reach their specific technical lifetime. As regards capacity additions in future scenarios, we draw on real project data wherever possible. The remaining differences between the block-sharp plant list and aggregate NEP figures are compensated by adding as many stylized blocks as necessary. For reasons of simplicity and traceability, we assume uniform $500 \mathrm{MW}$ block sizes for all technologies. In the 2030 scenario, 5 such generic blocks are required for lignite, 12 for hard coal, 15 for CCGT and 14 for OCGT. ${ }^{9}$

Power plants that operate in a combined heat and power (CHP) mode are subject to additional operational constraints, depending on daily average ambient temperatures of the year 2010 and a respective district heating demand profile of a large German municipality. Importantly, we hold the overall CHP capacity constant in all scenarios. While this approach may not be particularly realistic given the German government's plans to increase power generation from CHP, it allows reducing complexity and eases comparisons between the scenarios. What is more, properly modeling future changes of CHP restrictions due to additional heat storage facilities or other flexibilization measures would pose considerable methodological and data-related challenges. Accordingly, it appears to be justified not to vary CHP restrictions between the scenarios. ${ }^{10}$

\subsection{Cost assumptions}

Fuel and carbon price assumptions are derived from NEP by means of linear interpolation (Table 1). Renewables are assumed not to incur marginal costs. Yet in case of biomass, there is a yearly energy cap which implies a shadow price of biomass (see section 3.3).

Table 1: Fuel and carbon prices (50 Hertz et al. 2013)

\begin{tabular}{llrrr}
\hline & Unit & $\mathbf{2 0 1 0}$ & $\mathbf{2 0 2 0}$ & $\mathbf{2 0 3 0}$ \\
\hline Lignite & $\mathrm{EUR}_{2010} / \mathrm{MWh}_{\text {th }}$ & 1.5 & 1.5 & 1.5 \\
Hard coal & $\mathrm{EUR}_{2010} / \mathrm{MWh}_{\text {th }}$ & 10.4 & 9.9 & 10.5 \\
Natural gas & $\mathrm{EUR}_{2010} / \mathrm{MWh}_{\text {th }}$ & 21.0 & 24.8 & 26.2 \\
Oil & $\mathrm{EUR}_{2010} / \mathrm{MWh}_{\text {th }}$ & 38.3 & 46.7 & 57.0 \\
$\mathrm{CO}_{2}$ certificates & $\mathrm{EUR}_{2010} / \mathrm{t}$ & 13.0 & 23.8 & 40.8 \\
\hline
\end{tabular}

As regards unit commitment modeling of thermal plants, four parameters are of particular importance: minimum load requirements, minimum offtime, start-up fuel costs and start-up depreciation costs (Table 2). Under baseline assumptions, these unit commitment parameters, which draw on DIW Berlin's own database and Schröder et al. (2013), do not change in future scenarios. In a sensitivity analysis, we use lower minimum load parameters.

\footnotetext{
${ }^{9}$ A block size of $500 \mathrm{MW}$ is typical for state-of-the art CCGT plants, which are most relevant here. For example, actual German CCGT projects in Bremen, Düsseldorf, Köln, Burghausen, Ulm, Karlsruhe, Krefeld and Leverkusen all have block sizes of 425-600 MW according to the German Association of Energy and Water Industries (BDEW). For hard coal and lignite plants, a block size of $500 \mathrm{MW}$ appears to be at the lower end of actual coal projects. Yet these additional blocks can partly be interpreted as a correction of different assumptions on the technical lifetime between NEP and DIW's database. In fact, NEP's "B" scenario does not foresee any lignite new-built. Compared to the average size of existing plants, a generic size of $500 \mathrm{MW}$ appears appropriate. For further discussion, see section 5 .

${ }^{10}$ Our approach may also be interpreted as follows: a possible future expansion of the German CHP fleet is counterbalanced by increasing CHP flexibility, such that the absolute level of CHP-restricted power generation does not change between 2010 and 2030.
} 


\begin{tabular}{lrlrr}
\hline & $\begin{array}{l}\text { Minimum } \\
\text { load (\%) }\end{array}$ & $\begin{array}{l}\text { Minimum } \\
\text { offtime } \\
\text { (hours) }\end{array}$ & $\begin{array}{l}\text { Start-up fuel } \\
\text { requirement for } \\
\text { cold start } \\
\text { (MWh }\end{array}$ & $\begin{array}{l}\text { Start-up } \\
\text { depreciation } \\
\text { costs (€/MW) }\end{array}$ \\
\hline Nuclear & 50 & 10 & 16,7 & 50 \\
Lignite / hard coal > 500 MW & $40 / 38$ & 8 & 5,9 & 49 \\
Lignite / hard coal $\leq \mathbf{5 0 0 ~ M W ~}$ & $40 / 38$ & 6 & 2,7 & 105 \\
CCGT & 45 & 2 & 2,8 & 60 \\
Other steam turbines & 38 & 2 & 2,8 & 57 \\
Gas turbines & 20 & 0 & 0,1 & 24 \\
\hline
\end{tabular}

Start-up costs depend on fuel and $\mathrm{CO}_{2}$ prices as well as depreciation costs. In reality, start-up costs depend on offtime, i.e. on a generator's temperature at the time it is started up again. As modelling offtime-dependent start-up costs is computationally demanding, we use a simplified approach: nuclear plants are generally assumed to carry out only hot starts, requiring only $30 \%$ of the cold-start fuel requirement provided in Table 2. Lignite and hard coal plants are assumed to carry out warm starts with $50 \%$ of the typical cold-start fuel requirement. Only generators fueled by natural gas and oil are assumed to typically carry out cold starts, incurring $100 \%$ of the start-up fuel requirements presented in the table. ${ }^{11}$

\subsection{Power generation from renewable sources}

Hourly power generation from fluctuating renewables is based on actual 2010 feed-in data provided by German TSOs. ${ }^{12}$ Hourly availability factors are calculated by relating hourly feed-in to respective installed capacity. Using official end-of-year capacity data, we assume a linear capacity increase throughout the year. Hourly availability factors are then multiplied with installed capacities shown in Figure 1.

As regards power generation from biomass, we use yearly energy caps of 34 TWh in 2010 and 57 TWh in 2030. In the 2010 scenario, we assume generators to be completely inflexible, i.e. hourly generation from biomass is fixed to a yearly average level. This reflects actual incentives of biomass power plants in 2010 caused by a time-invariant feed-in tariff. In future scenarios, we assume biomass to be more flexible, reflecting changes in the legislation. ${ }^{13}$ In 2020 , half of the available energy cap is assumed to be used flexibly, and the other half is fixed to a yearly average value. In 2030, the yearly biomass cap can be allocated fully flexibly among hours, only restricted by available generation capacity (equation 8). Run-of-river hydro power generators are assumed to produce at constant hourly levels which vary between the 13 modeled 4-week sequences according to historic data.

\footnotetext{
${ }^{11}$ With 2010 cost data, this results in typical start-up costs of around $€ 250,000$ for a $1 \mathrm{GW}$ nuclear block, $€ 50,000$ or 70,000 for $800 \mathrm{MW}$ lignite or hard coal blocks, and €60,000 for a $500 \mathrm{MW}$ CCGT block.

${ }^{12}$ In the case of offshore wind power, we use 2012 data as installed capacities of 2010 were extremely small.

${ }^{13}$ According to the current Renewable Energy Sources Act (EEG), all new biomass power plants now receive a sliding market premium instead of a feed-in tariff. Moreover, the EEG provides a so-called flexibility premium which gives incentives to design the plants for higher peak loads and lower full load hours.
} 


\subsection{Load and exchange data}

Hourly load is assumed not to change compared to 2010 levels with a total yearly net consumption of around 561 TWh including grid losses. The hourly profile is taken from 2010 data publicly provided by German TSOs. The same is true for net power exchange with neighboring countries. Hourly exchange values are fixed to 2010 levels also in 2020 and 2030. Under such assumptions, the share of fluctuating renewables (wind power and PV) quadruples from 9\% (50 TWh) in 2010 to 37\% (206 TWh) in the 2030 baseline. Including biomass and hydro power, the respective overall renewable shares are $19 \%$ in 2010 and $51 \%$ in 2030.

\subsection{Additional model runs}

We also carry out additional model runs in order to separate overlapping effects of changing model inputs between 2010 and 2030 with respect to fluctuating renewables, biomass, pumped storage, thermal power plant portfolio as well as fuel and carbon prices. More precisely, we start with the 2010 baseline scenario and first decompose the effects of larger capacities of fluctuating renewables by increasing onshore and offshore wind power as well as photovoltaics capacities to 2030 levels, but holding all other input parameters constant at 2010 levels. Building on this setting, generation from biomass is flexibilized to 2030 assumptions in the next model run. In additional runs, the pumped storage capacity, the thermal plant portfolio and finally fuel and carbon prices are successively changed to the respective 2030 baseline levels. ${ }^{14}$

Aside from these baseline decomposition runs, we carry out different sensitivities for the years 2020 and 2030 in order to assess the effects of alternative flexibility assumptions:

- "More RES": Here we assume that the capacities of fluctuating renewables, i.e. onshore wind power, offshore wind power and PV, are 10\% larger compared to the baseline in 2020 and $20 \%$ larger in 2030. Accordingly, the need for flexibility in the system should increase.

- "Less storage": In this sensitivity we assume that the capacity of pumped hydro storage remains constant at the 2010 level. As a consequence, storage capacity is $40 \%$ lower in 2030 compared to the baseline. This reflects the fact that pumped storage capacity expansions are currently not economic in Germany. In fact, there have not been any investment decisions worth mentioning in German pumped storage projects in recent years.

- "Lower minload": The minimum load level of all thermal power plants is assumed to decrease by $25 \%$ compared to the baseline in 2020 and by $50 \%$ in 2030 . This sensitivity takes into account that the future flexibility characteristics of the German power plant portfolio are highly uncertain. Minimum generation levels may decrease either due to retrofits of existing plants or because of new-builds that are designed for increased flexibility.

- "Less curtailment": While curtailment of fluctuating renewables does not incur any direct costs under baseline assumptions, it is penalized in the objective function in this sensitivity. Such costs can be caused by renewable support schemes, i.e. feed-in tariffs or market premiums. To fully reflect the real situation in Germany, a thorough assessment of current and future support instruments and their respective levels would be required, differentiating between technologies, age classes and plant sizes. Instead, we use stylized, technologyinvariant penalties of $€ 100 / \mathrm{MWh}$ or $€ 1000 / \mathrm{MWh}$. While the first is intended to reflect in a

\footnotetext{
${ }^{14}$ The results of this decomposition analysis depend on the particular sequence of changing input parameters. While it appears intuitive to start with the effects of renewable expansion, other sequences would in general also be possible.
} 
rather coarse way the effects of actual German renewable support schemes, the latter represents an extreme assumption of a strong political preference for integrating as much fluctuating renewable power as possible into the system. ${ }^{15}$

The model is implemented as a mixed-integer linear program (MILP) in the General Algebraic Modeling System (GAMS) and solved with the commercial solver CLPEX. ${ }^{16}$

\section{Results}

\subsection{Baseline scenarios}

We first look at baseline scenario results. ${ }^{17}$ Despite a quadrupling share of fluctuating renewables between 2010 and 2030, the overall yearly number of start-ups of thermal power plants decreases from more than 3241 in 2010 by roughly a third to $2105(-35 \%)$ in 2020 and subsequently hardly changes to 2245 (-31\% cp. to 2010) in 2030 (Figure 2). The picture looks different for specific technologies. While the number of start-ups increases for lignite plants-these are running in a constant base-load mode in 2010-it decreases for hard coal plants and roughly stays constant in 2030 and 2010 for CCGT plants. The number of OCGT start-ups, in contrast, decreases substantially.

These developments, which may appear counterintuitive at first glance, are driven by exogenous changes in the power plant portfolio. On the one hand, we assume increasing block sizes of thermal power plants, as described in section 3. On the other, the NEP foresees a substantial capacity decrease of nuclear and-to a smaller extent-hard coal and lignite plants between 2010 and 2030, combined with much-increased capacities of fluctuating renewables and CCGT plants. Accordingly, the operational patterns of hard coal plants change from a mid-load position with regular daily cycles to longer cycles, albeit hard coal full-load hours decrease slightly. CCGT plants balance a substantial part of renewable fluctuations, which tends to increase their cycling needs; but at the same time, CCGT plants partly substitute for nuclear and coal-fired capacity decreases, i.e. serve a part of the remaining base- and mid-load patterns. In sum, and combined with increasing block sizes, the number of CCGT start-ups does not change much. A notable decline is observed for OCGT plants. Yet this development may at least partly be considered a modeling artefact. In the 2010 scenario, which largely reflects the real German power plant portfolio of this year, some fraction of the yearly peak load is served by existing small-scale gas-fired OCGTs. In the 2030 scenario, OCGT plants on the one hand have larger average block sizes; on the other, their share in overall power generation strongly decreases because of a substantial increase in CCGT plants, which serve most of residual peak load.

\footnotetext{
${ }^{15}$ Egerer and Schill (2014) also use the values $€ 100 / M W h$ and $€ 1000 / M W h$ to study the effect of lower renewable curtailment on dispatch and investment decisions. For scenarios of 2024 and 2034 they show that the marginal system costs of reducing renewable curtailment increase strongly, whereas overall renewable shares hardly change.

${ }^{16}$ GAMS code and all input parameters are available from the corresponding author upon request.

${ }^{17}$ In order to improve readability, the figures provided below generally do not show results for oil-fired generators, as these play a negligible role in all scenarios.
} 


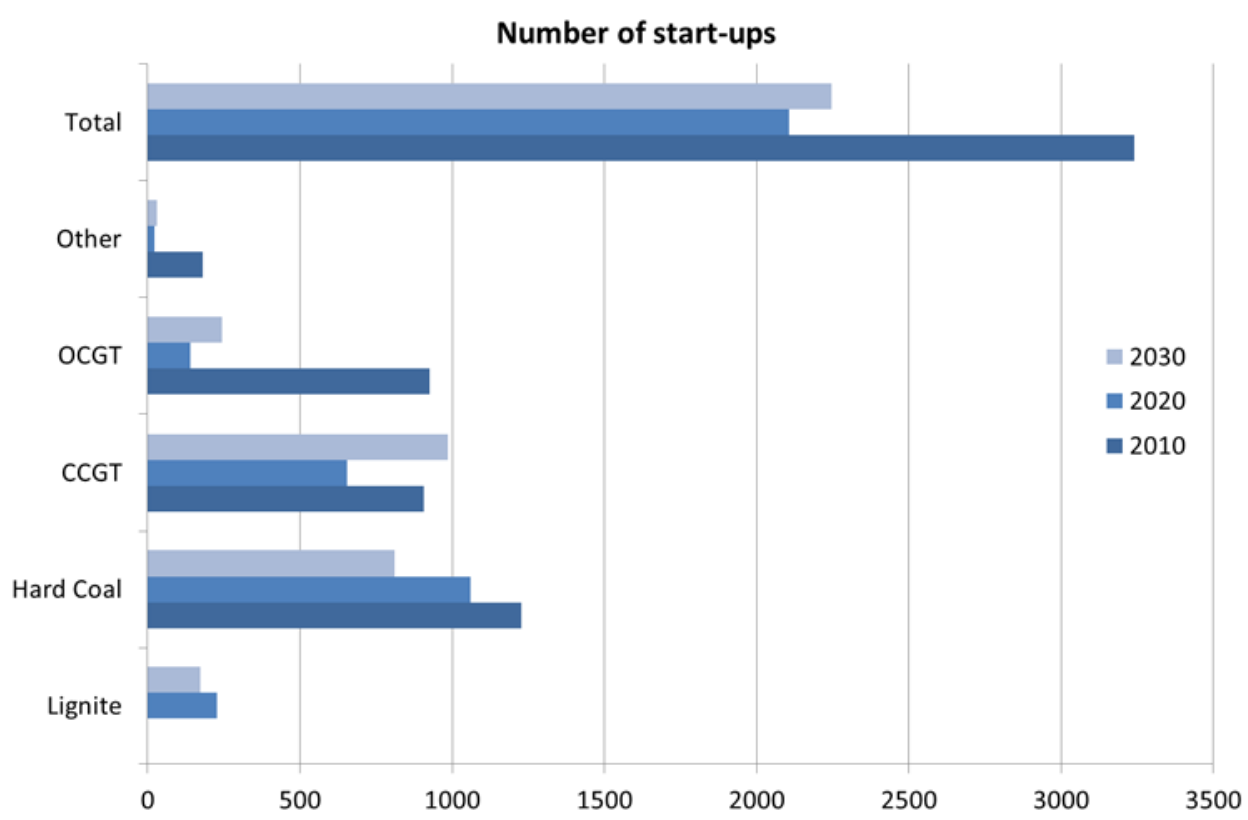

Figure 2: Yearly number of start-ups in the baseline scenarios

While the overall number of start-ups decreases between 2010 and 2030, total yearly start-up costs in the modeled German power system markedly increase from around €86 million in 2010 to €94 million (+10\%) in 2020 and $€ 125$ million (+46\%) in 2030 (Figure 3). Differences to the aforementioned development of start-up numbers can partly be explained by the fact that increasing block sizes hardly have an effect on start-up costs. Furthermore, results are driven by a shift toward CCGT plants and by fuel and carbon price increases assumed in the NEP. The latter are particularly pronounced for natural gas, where fuel and $\mathrm{CO}_{2}$ price changes contribute roughly equally to higher start-up costs.

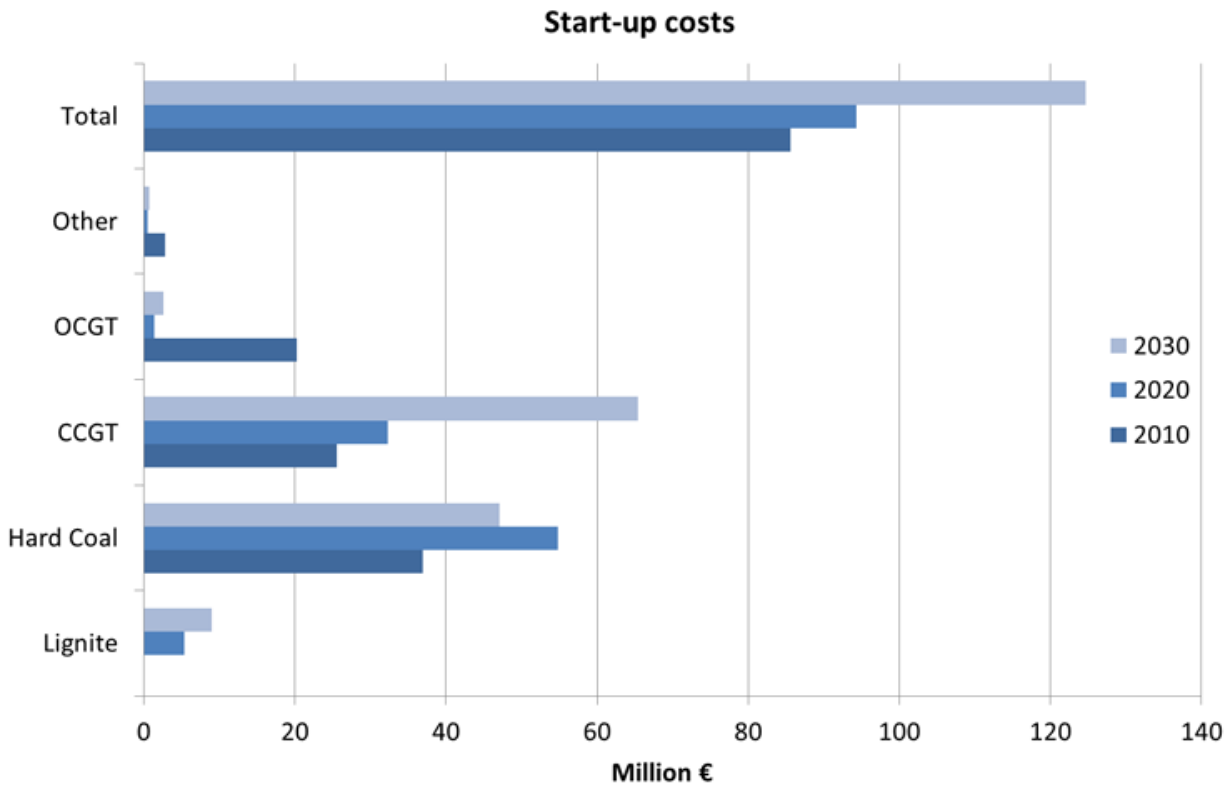

Figure 3: Yearly start-up costs in the baseline scenarios 
Relating start-up costs to overall yearly variable costs of power generation shows that the relative relevance of start-up costs, on average, increases only slightly. This is because increasing fuel and carbon prices not only have an effect on start-up costs, but also on other variable generation costs. On average, the share of start-up costs grows from around $0.8 \%$ to $0.9 \%$ (Figure 4). Accordingly, the assumed power system changes in the context of the German energy transition do not have a major impact on the relative relevance of start-up cost under baseline assumptions. Yet there are some differences between the respective thermal technologies. For lignite, the share remains particularly low at $0.3 \%$ in 2030 , while it increases from $1.3 \%$ to $1.7 \%$ for CCGT plants.

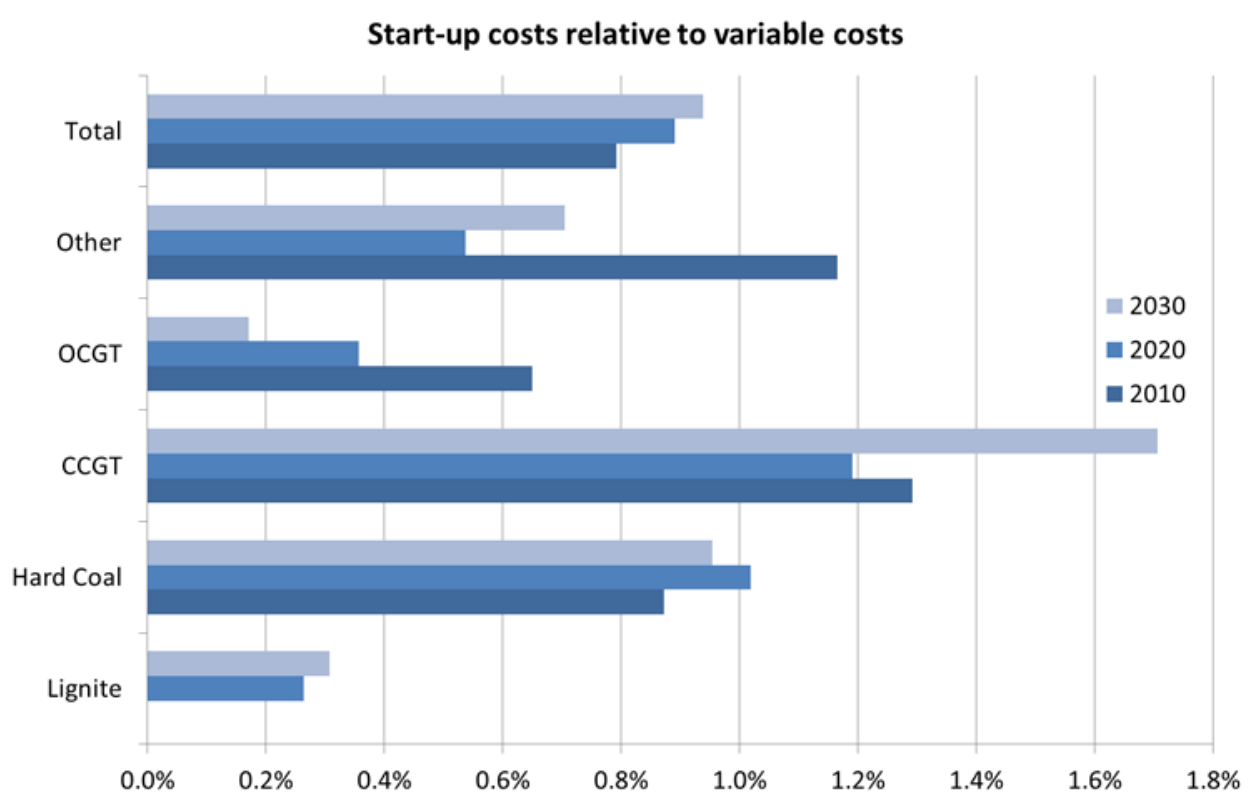

Figure 4: Yearly start-up costs relative to yearly variable costs of the respective thermal technology

As introduced in section 3, an evaluation of additional model runs allows separating some overlapping effects. Ceteris paribus-i.e., with an unchanged remaining portfolio-the expansion of fluctuating renewables would increase the overall yearly number of start-ups by $41 \%$ (Figure 5). This result is intuitive given the exogenous growth in renewable variability, and it supports previous qualitative statements in the literature (cp. Pérez-Arriaga and Batlle 2012). Changes of other assumptions, however, have countervailing effects. For example, the assumed flexibilization of biomass power plants and the increased pumped hydro capacity serve as additional flexibility options which together already offset most of the increase in cycling needs triggered by renewable expansion. A particularly large reduction is caused by the assumed changes of the thermal power plant portfolio, i.e. the shift from nuclear, lignite and hard coal to CCGT plants, together with a general increase of block sizes. Under ceteris paribus assumptions, the expansion of fluctuating renewables would trigger a particularly strong increase in lignite start-ups, which is largely equalized again under the assumed 2030 portfolio changes. This is mainly caused by increasing lignite block sizes due to shutdowns of smaller old plants and larger new-builds. Average lignite block size grow 
from $333 \mathrm{MW}$ in 2010 to $519 \mathrm{MW}$ in 2030, while average CCGT blocks increase from $226 \mathrm{MW}$ to 368 MW. Changing fuel prices only have a small effect, i.e. they hardly alter the dispatch merit order.

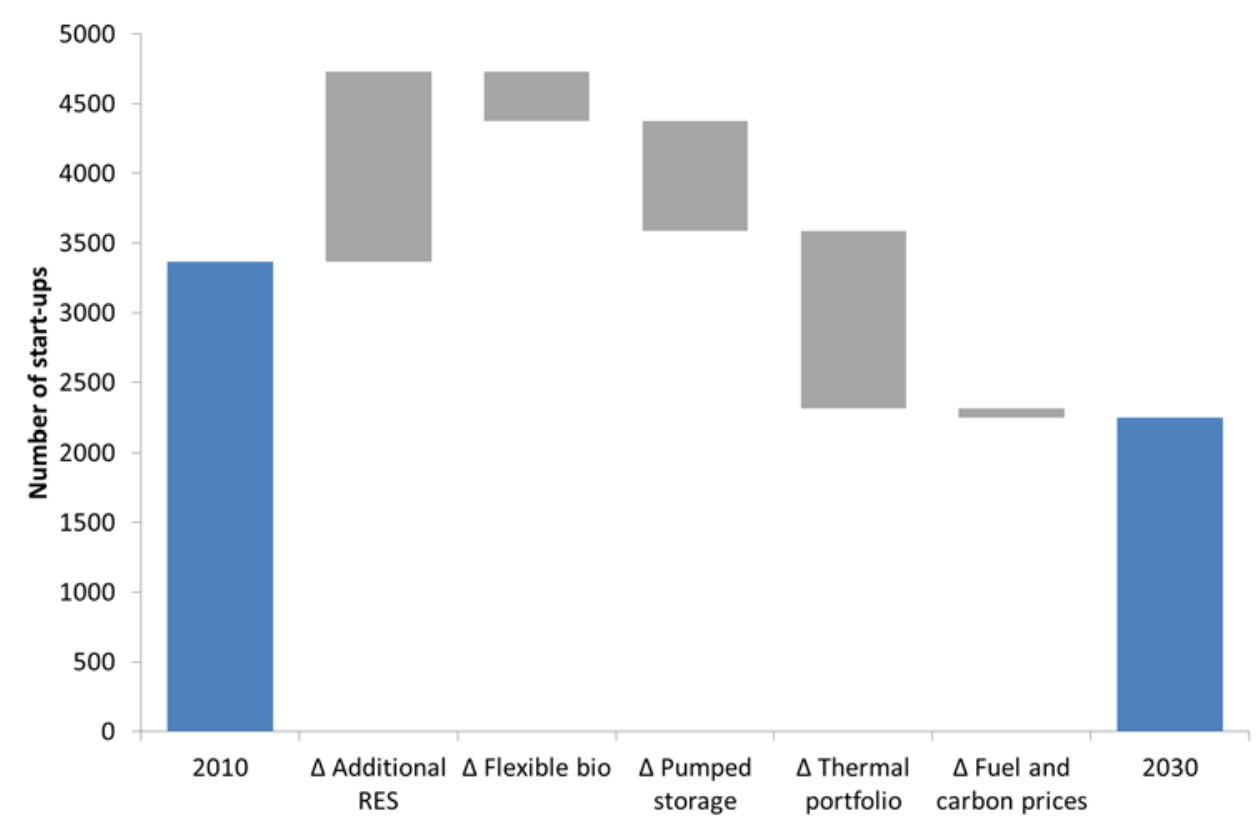

Figure 5: Separation of effects between 2010 and 2030 baseline scenarios: number of start-ups

Focusing on start-up costs instead of the number of start-ups, the separation exercise shows a slightly different picture (Figure 6). While the effects of most parameter changes have the same direction as discussed above, the assumed fuel price increase has an increasing effect. The reason is that higher fuel and carbon prices, in particular in the case of CCGT plants, directly translate into higher start-up fuel costs. In addition, renewable expansion alone would nearly double start-up costs (+93\%). This increase attributable to renewables is much larger than the corresponding effect on the number of start-ups because of strongly increased cycling of base-load plants which incur relatively high costs per start-up under ceteris paribus (2010) assumptions. In contrast, the thermal power plant portfolio change has a much smaller negative effect compared to Figure 5 because of increasing block sizes hardly matter for start-up costs. The thermal portfolio effect is furthermore over-compensated by increasing fuel and carbon prices. These effects sum up to increasing overall start-up costs, despite a corresponding decrease of start-up events. Yet the relative cost increase is much smaller than the growth in fluctuating renewable power. 


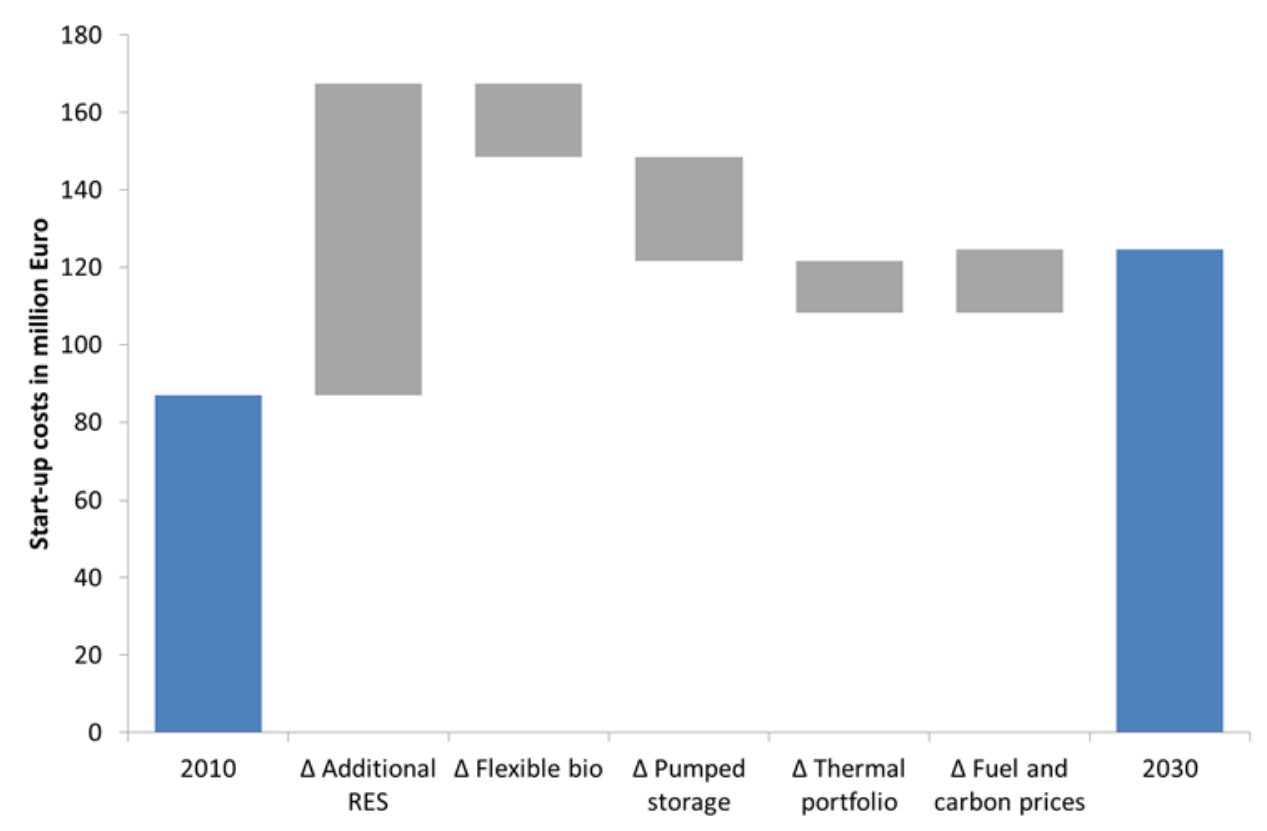

Figure 6: Separation of effects between 2010 and 2030 baseline scenarios: start-up costs

\subsection{Sensitivity analyses}

To some degree, overall results are sensitive to deviating assumptions on renewable expansion, storage capacity deployment and changes in the minimum load level of thermal power plants, and less so with respect to decreased renewable curtailment. Yet effects vary substantially for different technologies. The "More RES" sensitivity assumes additional capacities of fluctuating renewables of $+10 \%$ by 2020 and $+20 \%$ by 2030 , which can be interpreted as an accelerated transition from fossil to renewable power sources. The overall number of required start-ups increases a little more than proportionally by $+10 \%$ and $+25 \%$. This is largely driven by increased cycling needs of lignite and hard coal plants, i.e. former base- and mid-load generators (Figure 7). Lignite plants show the highest relative increase, with the number of start-ups more than doubling between the 2030 baseline and the respective "More RES" sensitivity. That is, an expansion of fluctuating renewables-ceteris paribus-predominantly increases the cycling needs of base-load technologies with low variable costs. This reconfirms earlier findings in other power systems (cp. Troy et al. 2010). 


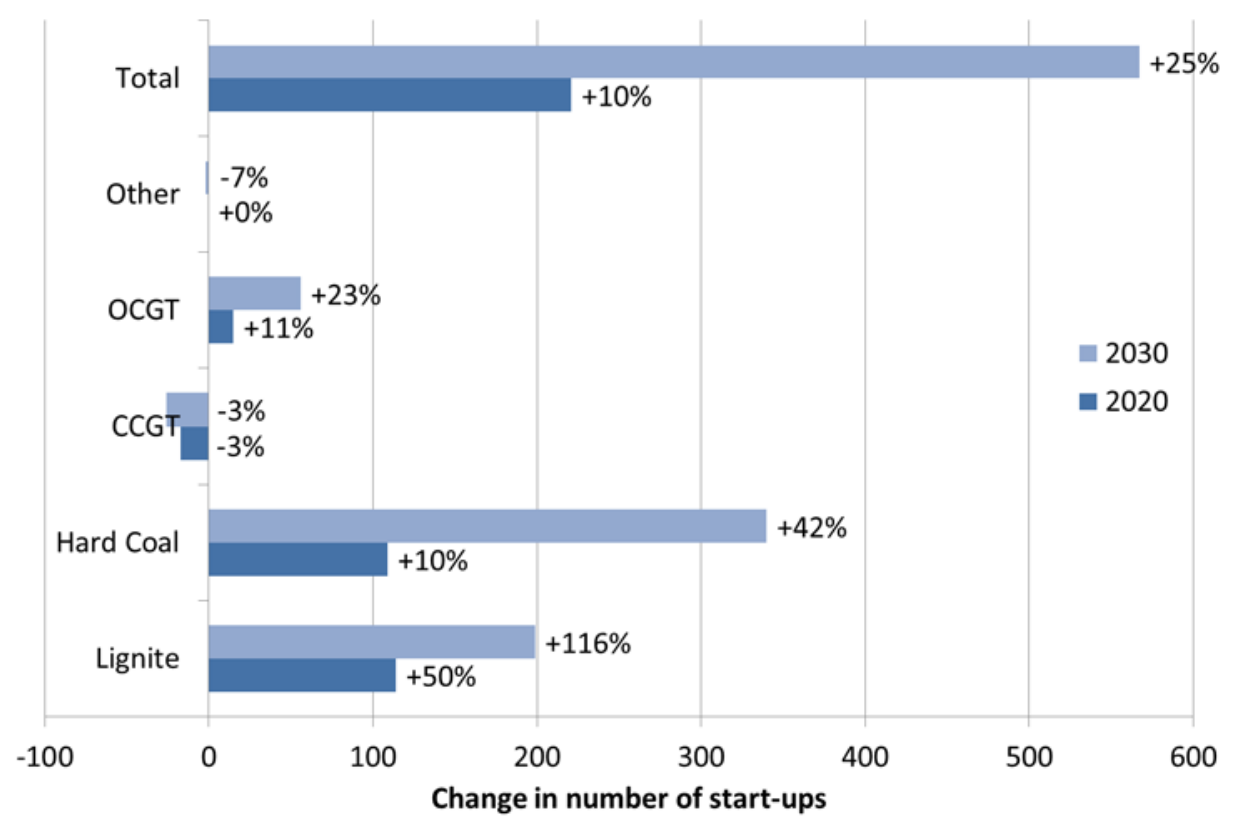

Figure 7: "More RES": Absolute and relative change in the yearly number of start-ups compared to respective 2020 and 2030 baseline scenarios

Assuming "Less storage", i.e. abstracting from future storage expansion, leads to an overall increase of start-ups comparable to the one observed in the "More RES" sensitivity (Figure 8). In 2030, the assumed decrease in storage capacity of around $40 \%$ compared to the baseline results on average in a $27 \%$ increase of start-up events. That is, thermal cycling needs grow either because of additional, renewable-induced flexibility requirements or due to supply-side flexibility losses. Yet the distribution of changes among generation technologies is rather different compared to "More RES". Under the assumption of lower storage capacities, OCGT plants show the largest increase in cycling needs, both in absolute and relative terms, followed by CCGT, hard coal and lignite plants. In other words, flexible gas-fired plants have to provide a substantial part of the flexibility that is provided by additional storage in the baseline. Storage and gas-fired power plants may thus be considered as competing flexibility options. ${ }^{18}$ The more power storage in the system, the less cycling of gas-fired plants is required, and vice versa. ${ }^{19}$ While the motivation of this sensitivity is rather specific to the current German situation, results may be considered to have a rather general character.

\footnotetext{
${ }^{18}$ Other analyses have come to similar conclusions, for example, Egerer and Schill (2014) who also consider investment decisions. A comparable effect is likely to occur with respect to different assumptions of demandside flexibility, as the power system effects of storage and load shifting are very similar.

${ }^{19}$ Troy et al. (2010) conversely argue that lower storage capacities may in specific settings decrease the cycling needs of coal-fired plants until very high wind shares are reached. In their analysis of the Irish system, this finding is driven by primary reserve provision of coal plants.
} 


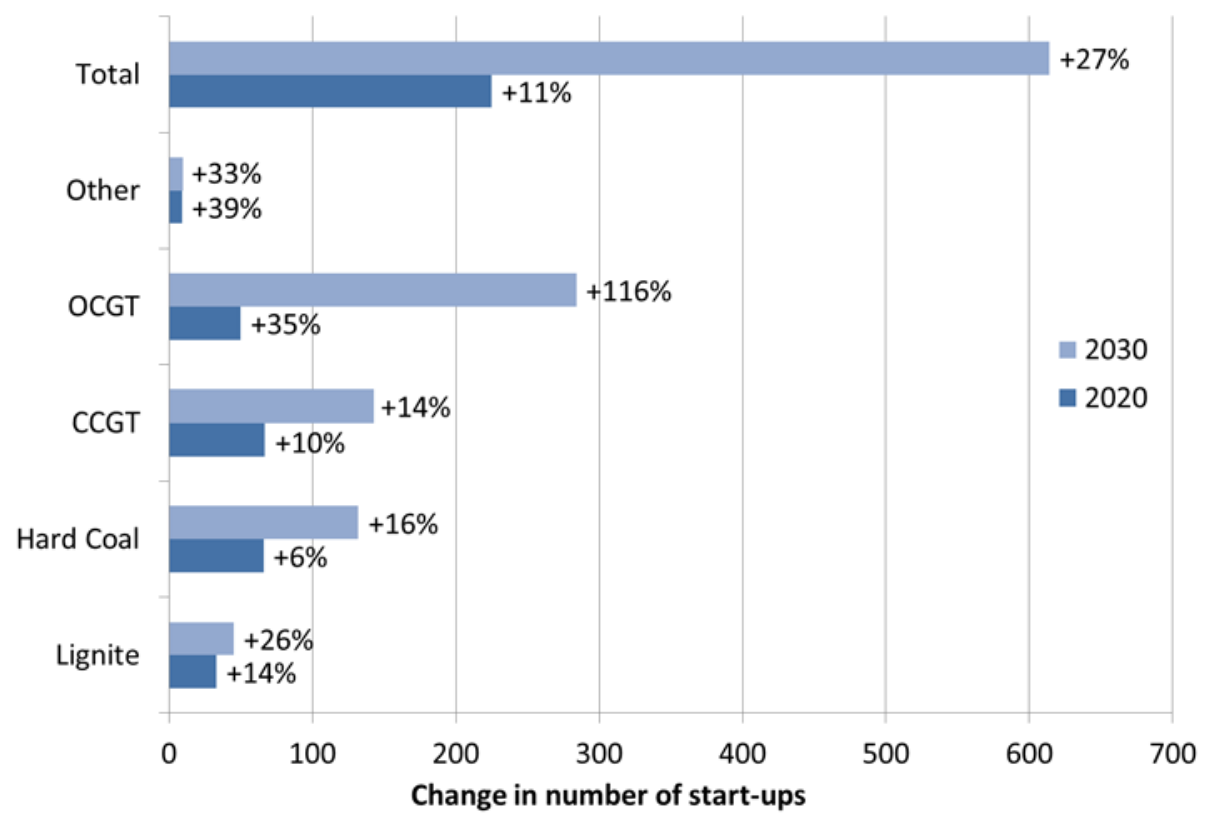

Figure 8: "Less storage": Absolute and relative change in the yearly number of start-ups compared to respective 2020 and 2030 baseline scenarios

Results of the "Lower minload" sensitivity indicate that increasing flexibility of thermal power plants has an opposite effect on cycling needs as compared to the previously discussed sensitivities (Figure 9). Under the assumption of decreased minimum load requirements of $-25 \%$ in 2020 and $-50 \%$ in 2030 compared to the baseline, the overall number of start-ups is substantially reduced as more generators remain online in periods of low residual load. In the 2030 model runs, the absolute effect is most pronounced for CCGT and hard coal plants, which can be considered as some kind of midload generators in this setting. Lignite plants have the strongest relative decrease with less than half the number of start-ups in 2030. This means that decreased minimum load requirements would allow lignite plants to largely preserve their position as base-load generators even under substantial expansion of fluctuating renewables. It should be noted that such increased flexibility of thermal plants may involve not only additional investments, but also additional variable costs due to decreased thermal efficiency which we abstract from in this analysis. 


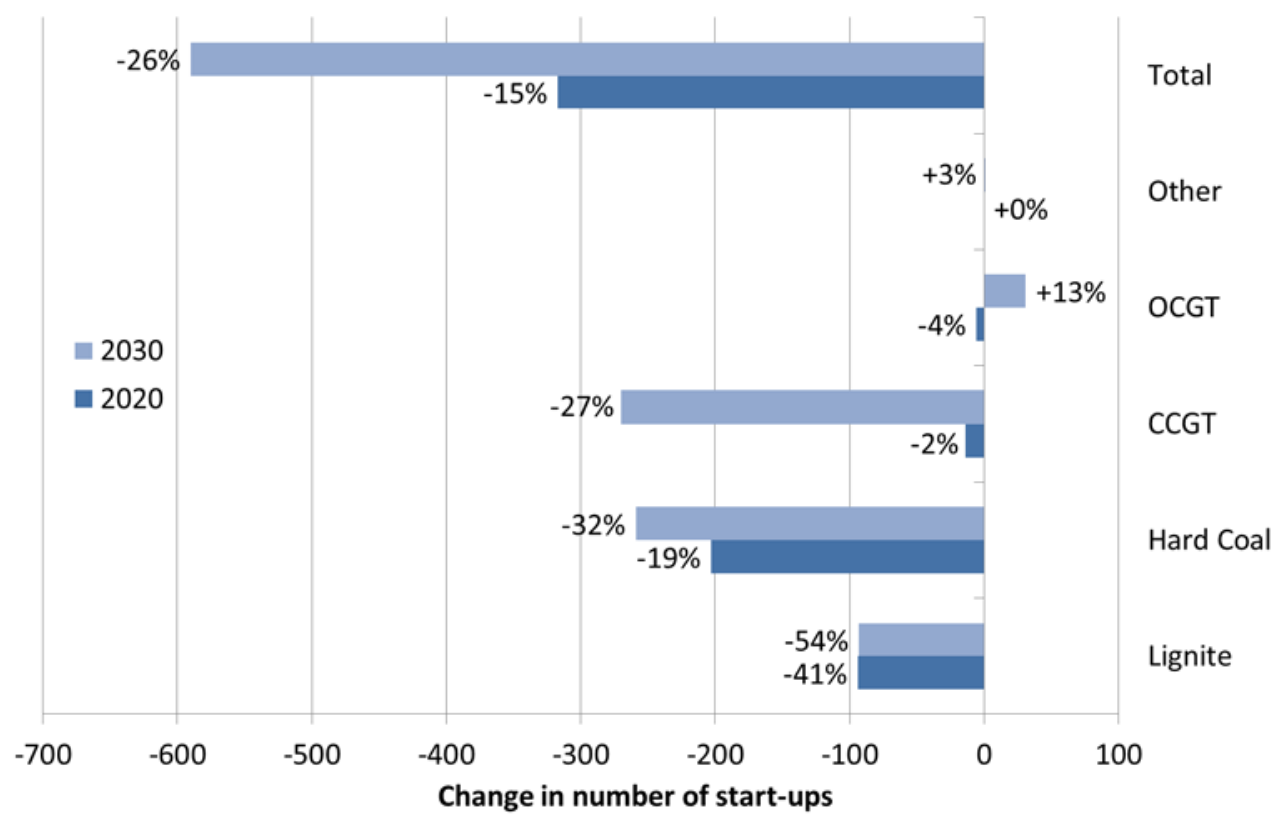

Figure 9: "Lower minload": Absolute and relative change in the yearly number of start-ups compared to respective 2020 and 2030 baseline scenarios

Finally, the "Less curtailment" sensitivity shows that sub-optimal (i.e., too little) temporary curtailment of renewable surpluses has a comparatively small effect on model outcomes (Figure 10). Assuming a curtailment penalty of $€ 100 / \mathrm{MWh}$ in the objective function, the overall number of startup procedures increases by only $+1 \%(+3 \%)$ in 2020 (2030) compared to the baseline. The effect of actual renewable support schemes in Germany on curtailment-related start-ups should thus be rather small. ${ }^{20}$ Even under the rather extreme penalty assumption of $€ 1000 / \mathrm{MWh}$, total start-ups would increase by only $+2 \%(+6 \%)$ in 2020 (2030). Renewable curtailment is generally low because of very steep surplus-duration curves with high hourly peak surpluses and comparatively low yearly surplus energy (cp. Schill 2014). Another reason for low curtailment-despite limited export opportunities-is the strong increase in pumped storage capacity assumed in the NEP scenarios. In the 2030 baseline, only around 0.5 TWh of fluctuating renewable energy has to be curtailed, corresponding to $0.2 \%$ of overall wind and solar power generation. This value decreases to $0.3 \mathrm{TWh}$ (0.1\%) under the assumption of a $€ 1000 / M W h$ curtailment penalty. ${ }^{21}$ Yet additional start-ups are not equally distributed between technologies, but focus on lignite plants both in absolute and relative terms. This is because these plants still have the lowest marginal costs in the 2030 scenario and are thus the last to go offline in periods of excess renewable supply. The interrelation between curtailing renewables and shutting down thermal power plants is accordingly most pronounced for lignite plants.

\footnotetext{
${ }^{20}$ Our analysis only provides a general indication as we, amongst other simplifications, do not differentiate between feed-in tariffs, which in general correspond to very high penalties in the objective function, and sliding market premiums, which limit negative prices to (negative) support levels. Irrespective of future changes in German renewable support policies, both schemes will still be present to some extent in the year 2030 due to their 20-year duration.

${ }^{21}$ Additional model runs with values up to $€ 1,000,000 / \mathrm{MWh}$ show that curtailment hardly decreases any further as the remaining peak surpluses cannot be integrated with the assumed storage capacities, irrespective of thermal start-up costs.
} 


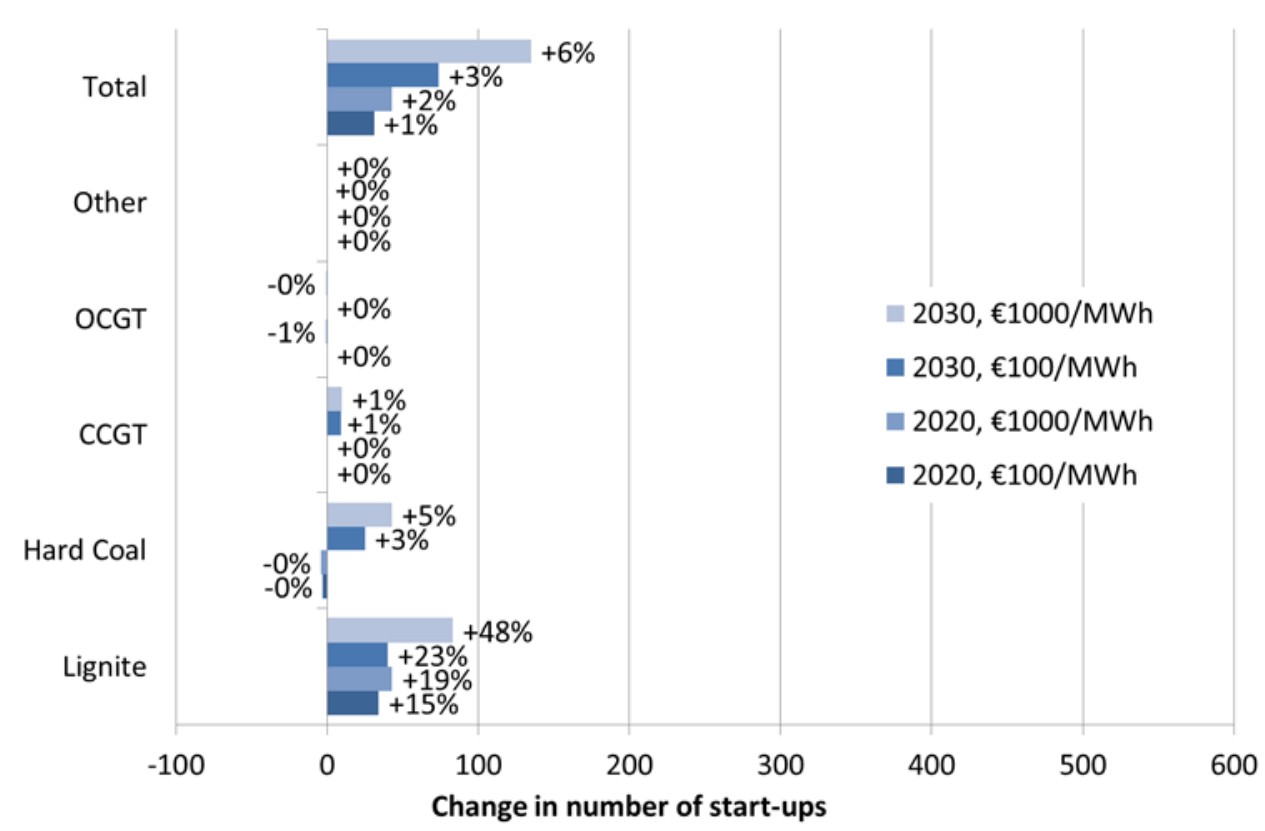

Figure 10: "Less curtailment": Absolute and relative change in the yearly number of start-ups compared to respective 2020 and 2030 baseline scenarios

\section{Discussion of limitations}

The model analysis requires a range of simplifying assumptions. For some of these, the direction in which results may be distorted is intuitive; for others, effects are less clear. To begin with, unit commitment models generally draw on stylized techno-economic parameters such as offtimes and start-up costs. These are hard to estimate bottom-up and may vary substantially between different block sizes, age classes, and manufacturers. Start-up fuel requirements in reality also depend on offtime duration, i.e. on plant temperature. Moreover, it is likely that the costs and restrictions related to thermal flexibility will change in the future, but how this may impact the respective unit commitment parameters-which are in any case stylized-is difficult to foresee.

To raise a more general point, some of the assumed technical constraints may not even exist in the real world. For example, the concept of minimum offtimes rather represents economic considerations (e.g., avoid unnecessary wear and tear) than physical realities. While unit commitment modelers aim to represent such intricate and plant-specific economic considerations by means of simple parameters and restrictions, it is not straightforward to estimate the qualitative effects of such simplifications on model outcomes. Likewise, drawing on exogenous-although established and policy-relevant-future power plant portfolios inherently leads to distorted outcomes as the portfolio is unlikely to resemble a long-term equilibrium. The NEP capacities used here may constitute a desirable development with respect to generation adequacy, but the actual realization of these capacities is uncertain. For example, lignite plants may be phased out earlier because of emission concerns. Accordingly, the shares of specific technologies and/or their flexibility characteristics may be either under- or overrated, with unclear consequences for start-up outcomes. In order to avoid these problems, using integrated investment and dispatch models would be desirable. Yet this requires alternative problem formulations in order to maintain computability (cp. Palmentier and Webster 2011). 
Another simplification more specific to the analysis made here relates to the assumption that CHP generation in future scenarios changes neither with respect to installed capacity nor with respect to flexibility. In the real German situation, both overall CHP generation and its flexibility should generally increase by 2030, for example due to additional heat storage. Yet it is unclear which of these effects dominates with respect to start-up costs.

The generic assumption of capacity additions in $500 \mathrm{MW}$ blocks in future scenarios is appropriate for CCGT (cp. footnote 9), but seems to be too small for new hard coal and lignite blocks and too high for OCGT plants. Accordingly, we may overestimate the number of start-ups for hard coal and lignite blocks and underestimate OCGT start-ups. Yet start-up cost results should not change much, as these increase linearly with block sizes. Moreover, OCGT plants do not play much of a role in the scenarios used here as their yearly power generation is very small.

One factor that generally leads to an underestimation of cycling needs and related costs is the assumption that thermal efficiency does not decrease during part-load operation. If this were to be considered, shutting plants down completely instead of operating them in part-load mode may become more attractive. Likewise, the hourly resolution used here underestimates sub-hourly renewable fluctuations and related cycling requirements. Deane et al. (2014) show that an increased temporal resolution leads to more realistic estimations of thermal cycling activities and related costs. In their Irish case study, increasing the temporal resolution from 60 to 5 minutes results in relative start-up cost increases of around $13 \%$.

In contrast, several limitations generally lead to an overestimation of cycling needs and start-up costs. A very important one is the assumption of fixed imports and exports in the 2020 and 2030 scenarios. Reasons for making this simplification include large uncertainties with respect to the future development of neighboring power systems as well as severe numerical challenges in solving pan-European unit commitment models. In general, power plants in neighboring countries are unlikely to be less flexible than German ones. In addition, the shares of fluctuating renewables in neighboring countries are likely to be lower than in Germany in the medium run (Denmark being a potential exception). Accordingly, we underestimate the flexibility potentials in the European interconnection and overestimate start-up costs in Germany. Likewise, we tend to overestimate flexibility requirements in Germany because of linearly scaling up feed-in patterns of variable renewables. Although this is rather common in the literature, it neglects potential future smoothing of these profiles related to alternative generator designs and different geographic distributions (cp. Schill 2014).

Another potential overestimation of start-up costs is caused by only considering thermal power plants and pumped storage as suppliers of flexibility. It is reasonable to assume that other types of power storage as well as demand-side flexibility potentials will increasingly play a role with larger shares of fluctuating renewables (compare Zerrahn and Schill 2015a). Yet properly modeling load shifting would not only require detailed techno-economic input data on specific power consumers, but also involves intricate model formulations which may increase the computational burden (cp. Zerrahn and Schill 2015b).

Comparing stochastic and deterministic model formulations, Abrell and Kunz (2015) show that startup cost outcomes are lower in stochastic models. The reason is that the optimal number of thermal plants operating at least in part-load mode is generally higher than in deterministic settings in order 
to be able to respond to uncertain short-term changes in power demand. Tuohy et al. (2009) make a similar point for stochastic wind power. As we use a deterministic model, this may contribute to an upward distortion of start-up cost outcomes. Abrell and Kunz (2015) also show that neglecting transmission constraints can cause similar upward distortions-although to a smaller extentbecause network-related redispatch measures may require additional plants to be online.

Further, results depend on assumed fuel and $\mathrm{CO}_{2}$ price developments. For instance, lower natural gas prices, which may be caused by increased shale gas exploitation, would generally lead to lower startup costs. Assessing the effects of higher $\mathrm{CO}_{2}$ prices would require further analyses, as this may change the dispatch merit order of lignite, hard coal and natural gas plants.

While a definitive assessment on the relative size of upward and downward distortions is not possible, it appears that there are generally more model limitations which lead to an overestimation of cycling needs than vice versa. The overall relevance of start-up costs may accordingly be somewhat overrated in this analysis. Yet we do not see any clear indication why the qualitative effects discussed in section 4 should change substantially if these limitations could be addressed.

\section{Conclusions}

We investigate how start-ups of thermal power plants change in the context of increasing shares of fluctuating renewables. To do so, we carry out a model-based analysis for mid-term scenarios of the German energy transition, based on the German Grid Development Plan, according to which the share of fluctuating renewables quadruples between 2010 and 2030. Under baseline assumptions, the overall number of yearly start-up procedures decreases by around a third, whereas total start-up costs increase nearly by half. Yet the relative share of start-up costs in overall variable costs of thermal power plants increases only slightly from $0.8 \%$ to $0.9 \%$.

We determine several overlapping and partly countervailing effects which drive these results. Under ceteris paribus assumptions-i.e., with an otherwise unchanged thermal power plant portfolio-the expansion of fluctuating renewables would have a strongly increasing effect on the number of startups, and even more so on start-up costs. In contrast, assumed future changes of the power plant portfolio have opposite effects. These include increased flexibility of biomass power plants, additional power storage capacities as well as increasing average block sizes.

We conclude that the relevance of start-up costs does not increase substantially in medium-term scenarios of the German energy transition modeled here. Yet this may change under alternative assumptions, for example regarding different developments of other flexibility options in the system both on the supply and demand side. Start-up costs generally increase in case of a stronger expansion of wind and solar power, lower power storage capacities, less flexible thermal power plants (including biomass), and lower renewable curtailment. As the increasing use of fluctuating renewables is not only a German phenomenon, but a global trend, these general findings are also relevant for other countries with thermal power systems that plan comparable transitions toward fluctuating renewables.

Our analysis may also be viewed in the context of the ongoing debate on the future design of power markets with large shares of fluctuating renewables. On the one hand, baseline findings indicate that the issue of start-up costs does not gain central importance even if the share of fluctuating renewables approaches $40 \%$. Growing quasi-fixed costs should thus not significantly increase the 
volume of complex bids and therefore may not affect market efficiency much more than is currently the case in most markets. As regards European power markets, the expansion of wind and solar power is thus unlikely to severely compromise the use of linear pricing in the medium run. On the other hand, our analysis also indicates that under alternative assumptions, start-up costs may grow both in absolute and relative terms. Accordingly, non-convex costs of thermal power plants, which have been investigated by energy economists for some time even in markets without wind and solar power, should also be properly addressed in future market designs for renewables-dominated systems. This would get particularly important if the main options expected to provide future power system flexibility-flexible thermal plants, storage, non-fluctuating RES like biomass, and the demand side-developed less favorably than generally assumed. Likewise, proper remuneration of start-up costs may become even more important in the longer run if the shares of fluctuating renewables increase beyond the levels modeled in this analysis. 


\section{Appendix}

Table 3: Sets, parameters, and variables of the basic model

\begin{tabular}{|c|c|c|}
\hline Sets & Description & Unit \\
\hline$i \in I$ & Set of thermal power plant blocks of various technologies & \\
\hline $\boldsymbol{j} \in \boldsymbol{J}$ & Set of thermal storage technologies & \\
\hline res $\in$ RES & Set of fluctuating renewable technologies & \\
\hline \multicolumn{3}{|l|}{ Parameters } \\
\hline avail $_{i, t}$ & Availability of thermal blocks & $\%$ \\
\hline availbio $_{t}$ & Availability of biomass generation & $\%$ \\
\hline $\operatorname{dem}_{t}$ & Hourly power demand & MWh \\
\hline energymaxbio & Yearly biomass power generation budget & MWh \\
\hline netexports $_{t}$ & Hourly net exports (exports minus imports) & MWh \\
\hline othergen $_{t}$ & Exogenous other hourly power generation (hydro, waste) & MWh \\
\hline penalty $_{\text {res }}$ & Penalty for renewable curtailment & $€ / \mathrm{MWh}$ \\
\hline $\operatorname{qmax}_{i}$ & Hourly Generation capacity of thermal blocks & $\mathrm{MWh}$ \\
\hline qmaxbio & Hourly generation capacity of biomass power plants & $\mathrm{MWh}$ \\
\hline $\operatorname{qmin}_{i}$ & Minimum hourly generation of thermal blocks & $\mathrm{MWh}$ \\
\hline resavail $_{\text {res }, t}$ & Hourly availability of fluctuating renewables & MWh \\
\hline$s c_{i}$ & Start-up costs of thermal blocks & $€$ \\
\hline $\operatorname{stinmax}_{j}$ & Hourly storage loading capacity & $\mathrm{MWh}$ \\
\hline stime $_{i}$ & Start-up time of thermal blocks (minimum off-time) & Hours \\
\hline stlevmax $_{j}$ & Maximum storage level & MWh \\
\hline stoutmax $_{j}$ & Hourly storage discharging capacity & MWh \\
\hline$v c_{i}$ & Variable generation costs of thermal blocks & $€ / \mathrm{MWh}$ \\
\hline vstc $_{j}$ & Variable generation costs of storage technologies & $€ / \mathrm{MWh}$ \\
\hline \multicolumn{3}{|l|}{ Binary variables } \\
\hline$S T_{i, t}$ & $\begin{array}{l}\text { Start-up variable of thermal blocks ( } 1 \text { if block is started up in period } t \text {, } \\
0 \text { otherwise) }\end{array}$ & \\
\hline $\boldsymbol{U}_{i, t}$ & Status variable of thermal blocks ( 1 if block is generating, 0 otherwise) & \\
\hline \multicolumn{3}{|c|}{ Continuous variables } \\
\hline Bio $_{t}$ & Generation from biomass & $\mathrm{MWh}$ \\
\hline Cost & Total dispatch costs & $€$ \\
\hline Rescurt $_{\text {res,t }}$ & Hourly curtailment of fluctuating renewables & MWh \\
\hline Resint $_{\text {res,t }}$ & Hourly system integration of fluctuating renewables & MWh \\
\hline$Q_{i, t}$ & Quantity of power generated by thermal block $\mathrm{i}$ in hour $\mathrm{t}$ & MWh \\
\hline $\operatorname{Stin}_{j, t}$ & Hourly power fed into storage & $\mathrm{MWh}$ \\
\hline Stlev $_{j, t}$ & Hourly storage level & MWh \\
\hline Stout $_{j, t}$ & Hourly power generation from storage & $\mathrm{MWh}$ \\
\hline
\end{tabular}




\section{Literature}

50Hertz, Amprion, TenneT, TransnetBW (2013): Netzentwicklungsplan Strom 2013. Zweiter Entwurf der Übertragungsnetzbetreiber. Berlin, Dortmund, Bayreuth, Stuttgart, 17.07.2013.

http://www.netzentwicklungsplan.de/NEP 20132 Entwurf Teil 1 Kap 1 bis 9.pdf

Abrell, J., Kunz, F. (2015): Integrating Intermittent Renewable Wind Generation - A Stochastic MultiMarket Electricity Model for the European Electricity Market. Networks and Spatial Economics 15(1), 117-147. http://dx.doi.org/10.1007/s11067-014-9272-4

Bertsch, J., (2014): Flexibility in Europe's power sector-An additional requirement or an automatic complement? Energy Economics. http://dx.doi.org/10.1016/j.eneco.2014.10.022

Deane, J.P., Drayton, G., Ó Gallachóir, B.P. (2014): The impact of sub-hourly modelling in power systems with significant levels of renewable generation. Applied Energy 113, 152-158.

http://dx.doi.org/10.1016/j.apenergy.2013.07.027

Egerer, J., Schill W.-P. (2014): Power System Transformation toward Renewables: Investment Scenarios for Germany. Economics of Energy \& Environmental Policy 3(2), 29-43.

http://dx.doi.org/10.5547/2160-5890.3.2.jege

IEA (2015): World Energy Outlook 2015. International Energy Agency, Paris.

Gribik, P.R., Hogan, W.W., Pope, S.L. (2007): Market-Clearing Electricity Prices and Energy Uplift. Harvard Working Paper. December 31, 2007.

Grimm, V., Ockenfels, A., Zoettl, G. (2008): Strommarktdesign: Zur Ausgestaltung der Auktionsregeln an der EEX. Zeitschrift für Energiewirtschaft 32(3), 147-161. http://dx.doi.org/10.1007/s12398-0080020-7.

Herrero, I., Rodilla, P., Batlle, C. (2015): Electricity market-clearing prices and investment incentives: The role of pricing rules. Energy Economics 47, 42-51.

http://dx.doi.org/10.1016/j.eneco.2014.10.024.

Kondziella, H., Bruckner, T. (2016): Flexibility requirements of renewable energy based electricity systems - a review of research results and methodologies. Renewable and Sustainable Energy Reviews 53, 10-22, http://dx.doi.org/10.1016/i.rser.2015.07.199.

Meeus, L., Verhaegen, K., Belmans, R. (2009): Block order restrictions in combinatorial electric energy auctions. European Journal of Operational Research 196(3), 1202-1206.

http://dx.doi.org/10.1016/j.ejor.2008.04.031

Milligan, M., Frew, B., Kirby, B., Schuerger, M., Clark, K., Lew, D., Denholm, P., Zavadil, B., O'Malley, M., Tsuchida, B. (2015): Alternatives No More: Wind and Solar Power Are Mainstays of a Clean, Reliable, Affordable Grid. IEEE Power and Energy Magazine 13(6), 78-87.

http://dx.doi.org/10.1109/MPE.2015.2462311 
O'Neill, R.P., Sotkiewicz, P.M., Hobbs, B.F., Rothkopf, M.H., Stewart Jr., W.R. (2005): Efficient marketclearing prices in markets with nonconvexities. European Journal of Operational Research 164(1), 269-285. http://dx.doi.org/10.1016/j.ejor.2003.12.011

Palmintier, B., Webster, M. (2011): Impact of unit commitment constraints on generation expansion planning with renewables. 2011 IEEE Power and Energy Society General Meeting, 1-7. http://dx.doi.org/10.1109/PES.2011.6038963

Pérez-Arriaga, I.J., Batlle, C. (2012): Impacts of Intermittent Renewables on Electricity Generation System Operation. Economics of Energy \& Environmental Policy 1(2).

http://dx.doi.org/10.5547/2160-5890.1.2.1

Schill, W.-P. (2014): Residual Load, Renewable Surplus Generation and Storage Requirements in Germany. Energy Policy 73, 65-79. http://dx.doi.org/10.1016/j.enpol.2014.05.032

Schill, W.-P., Gerbaulet, C. (2015): Power system impacts of electric vehicles in Germany: Charging with coal or renewables? Applied Energy 156, 185-196.

http://dx.doi.org/10.1016/j.apenergy.2015.07.012

Schröder, A., Kunz, F., Meiss, J., Mendelevitch, R., von Hirschhausen, C. (2013): Current and Prospective Costs of Electricity Generation until 2050. DIW Data Documentation 68.

http://www.diw.de/documents/publikationen/73/diw 01.c.424566.de/diw datadoc 2013-068.pdf

Stoft, S. (2002): Power System Economics. IEEE Press.

Troy, N., Denny, E., O'Malley, M. (2010): Base-Load Cycling on a System With Significant Wind Penetration. IEEE Transactions on Power Systems 25(2), 1088-1097.

http://dx.doi.org/10.1109/TPWRS.2009.2037326

Tuohy, A., Meibom, P., Denny, E., O'Malley, M. (2009): Unit Commitment for Systems With Significant Wind Penetration. IEEE Transactions on Power Systems 24(2), 592-601.

http://dx.doi.org/10.1109/TPWRS.2009.2016470

VTT (2009): Design and operation of power systems with large amounts of wind power. Final report, IEA WIND Task 25, Phase one 2006-2008. VTT Research Notes 2493.

Zerrahn, A., Schill, W.-P. (2015a): A Greenfield Model to Evaluate Long-Run Power Storage Requirements for High Shares of Renewables. DIW Discussion Paper 1457. http://www.diw.de/documents/publikationen/73/diw 01.c.498475.de/dp1457.pdf

Zerrahn, A., Schill, W.-P. (2015b): On the representation of demand-side management in power system models. Energy 84, 840-845. http://dx.doi.org/10.1016/j.energy.2015.03.037 